\title{
Do the cultural and behavioral factors have an impact on adoption of international accounting standards?
}

\author{
Olfa Riahi $^{1 *}$, Walid Khoufi ${ }^{2}$ \\ ${ }^{1}$ Doctor in Finance and Accounting - Tunisia \\ ${ }^{2}$ Professor at the Institute of Business Studies of Sfax - Tunisia \\ *Corresponding author E-mail: olfa-riahi@hotmail.com
}

\begin{abstract}
In this paper, we try to explain the effect of cultural and behavioral factors on the decision to adopt IFRS in developing countries until 2013. By using contingency theory and based on a sample of 77 developing countries, this head study allowed us to show that the behavioral factors, essentially accounting conservatism, are more dominant that cultural factors behind the decision to adopt IFRS by developing countries (DC).
\end{abstract}

Keywords: International Accounting Standards (IAS/IFRS); Developing Countries; Accounting Conservatism; Corruption; Culture.

\section{Introduction}

While developed countries have largely been appropriated in the movement of the implementation of accounting systems that reflect attributes of their environment, developing countries seem to be subject to the adoption of these systems, although they are invented for circumstances that are clearly more developed. Meanwhile, developing country markets have been targeted by the world's leading industries operating in saturated Western countries. To better carryout their activities in these countries, adoption of appropriate accounting standards will be essential.

This proves to be absurd for much it is generally accepted that the accounting practices cannot be developed in isolation, but should rather take into account the specific environment in which they s' run. According to this angle of analysis, it is possible to say that developing countries have adopted standards and accounting principles that are not necessarily derived of their national heritage. This rejects the interference environment in these countries (Hassab et al. 2003 ).

Therefore, and in our opinion, the accounting standards in most developing countries do not reflect a faultless harmony with the reality of a nation. It usually results from a search for legitimacy on the part of those States in the international community. This can predict that, specifically, the behavioral component that has the fundamental role in the adoption of IFRS by these countries.

This research is driven, firstly, by the will to discern why some developing countries are still far from adopting IFRS despite that they lead to improved quality of financial reporting, comparability, reliability and The relevance of the financial statements and, on the other hand, the scarcity of work, which has dealt with this issue within the framework of these countries. It should be noted that most previous studies are prescriptive or descriptive of the position of a particular country facing the international accounting standards (Zeghal and Mhedhbi, 2006).
At the present study, we strive to provide input to the oriented prior literature on the determinants of the choice of an accounting practice in a developing country echoing a new dimension which is the behavioral attribute.

The remainder of this paper is structured as follows: The second section will expose the objective and assumptions of research. The third section will present the methodology which is adopted. The fourth section focuses on the synthesis of the main empirical findings. Finally, in the fifth section, we present our main conclusions.

\section{Target and research hypotheses}

We will focus our study only on cultural and behavioral factors. Epistemologically, the conceptual framework of our research will be part of a descriptive perspective of different research studies have applied to the study of the impacts of cultural and behavioral factors on the adoption of international accounting standards by developing countries. Empirical studies on the factors favorable and unfavorable to the adoption of IFRS are rare.

The adoption movements of an accounting system centered on evolving, and complex principles push us to go beyond the traditional normative theories of accounting because they hardly retain the reality of practices to verify their assertions. To this end, we call for an integrative theory to explain the IFRS adoption in developing country's mechanism: contingency theory. However, this theory has called upon other theories during the exploratory process of reasoning of discovery or invention namely agency theory, neo-institutional theory and the theory of planned behavior. According to the contingency theory, the environment will affect the organizational structure of the company, but we can see that its impacts will be more compromising. In the literature, confirming or challenging the importance of environmental factors on the evolution of a country's accounting system, studies are generally descriptive of the impact of factors. However, a scarcity of efforts has been concerned through a quantifiable epistemology of discerning the interdependence of factors that would have accounted 
for differences in the accounting systems of countries. In order to achieve this, the various studies have sometimes been designed by explaining many environmental factors having an influence on the accounting systems, and at other times a single influence factor. Interviews throughout the literature on the various factors driving the adoption of IFRS are, on the one hand, that the majority of studies are primarily concerned with the cultural factor as with other factors, And that most researchers are interested in the effect of the environment on accounting in several countries (Hassab et al., 2003). It appears that the international accounting literature generally argues that accounting is largely influenced by the environment found in different countries. Alhashim and Arpan (1992) showed that the most predominant environmental factor influencing accounting is economic strength, social forces, legal system and culture. In fact, a majority of the writings have highlighted the importance of Factors of the institutional character (economic growth, educational level, Markets).

In order to develop and guide our assumptions, we refer us mainly to literature that analyzes the mutualism could be drawn between the evolution within the accounting system of a country and the characteristics of its environment. To achieve this, our analysis will be based on the assumption that the decision of a developing country to adopt IFRS is motivated by a specific set of environmental factors within a country that are cultural and behavioral only.

\section{Cultural factors}

Clearly, culture has been regarded as a factor that undoubtedly affects the development of accounting. However, it is not widely reported as a factor in the development of accounting systems. This can be explained by the complexity of cultural data that is affected by other influencing factors. It is generally accepted that culture is an important factor in the choice of an accounting system. Indeed, the countries belonging to a certain culture adop the accounting system inspired by the countries of the same cultural class (Nobes, 1998).

Lope s et al. (200 7) consider that cultural differences have a crucial role in the development of accounting systems. The study Parera et al. (2004) reveals that cultural dimensions play a negative role against the use of IFRS in developing countries.

To this end, the third hypothesis of our study will be as follows:

$\mathrm{H}$ 1. Cultural factors affect the use of international standards.

The implementation of all cultural factors proved very difficult because of the difficulty of measuring them. Three cultural variables will be chosen: education, religion and colonization. It is well known that the adoption of international accounting standards is a highly strategic and critical decision and requires a high level of education to be able to understand, interpret and make use of these standards (Zeghal, 2006).

In the literature, the level of education is often referred to as a factor in the development and design of an accounting system. Several studies (Mueller, GG Gernon, H. Meek, G (1987), Choi, DSF, Mueller, GG (1992) and Saudagaran, MS (2009)) agree that the absence of this factor can be a barrier limiting the evolution of accounting. Street (2002) recommended that the low level of education of accounting professionals in developing countries bother their Transition to IFRS. In 2004, Wong also demonstrated that education is seen as the major challenge against the adoption of IFRS in Turkey. In addition, Nobes (2004) noted that differences in education levels in developing countries significantly affect the adoption of IFRS. These reasoning lead us to think in a first sub-hypothesis that:

$\mathrm{H} 1$.1. The more a country exhibits a high level of education, the more it favors the adoption of IAS / IFRS.

Despite its rarity in accounting literature, religion has been considered by a number of researchers (C. Nobes 1998, A. Lau and R Ma 1997, RM Haniffa and TF Cooke 2002, B. Maali et al. S. Hamid et al 1993, S. Askary et al 2008; Ayadi and Ben Salem, 2012) as a crucial factor in the design of the accounting sys- tems of a region. The results found by Ayadi and Ben Salem $(2012)$ have revealed the existence of a positive and significant relationship between Christianity and the adoption of international accounting standards by countries that have already made a convergence strategy to this repository. In countries where religion is not Christian, there is a real obstacle to the adoption of IFRS. Thus, the two sub-assumptions below are to be inspected :

H1.2. the Christian religion has a significant influence on the choice of IAS / IFRS by developing countries

H1.3. Muslim developing countries will be less likely to adopt IFRS.

The political system as a factor of influence is often referred to in the literature as the colonial heritage (Nobes, 1998), and as such is considered to be a major factor in the evolution of accounting systems.

The impact of this factor is very evident throughout history. In addition to the imposition of their policy, the invading countries also impose their accounting doctrine. It is well known that several colonized countries have continued to use the same political and accounting system even though they are no longer adapted to their needs and the current economic situation.

The majority of the collections (A. Lau and R. Ma 1997, R. Taplin et al 2002, P. Walton and A. Haller 2003, J. Ashraf and WI Ghani 2005) have studied the involvement of colonization in the choice of accounting systems discerned the significant effect of US and UK colonization on the adoption of IFRS. Nobes (1983) similarly observed that countries attracted by the Anglo - Saxon tradition are the most intimate with international standards and are more adept at choosing them. Several other tests can be reported, including Chamisa (2000) and Hove (1986) who exhibited that adopting IFRS standards would be easier for developing countries under an Anglo-American culture.

From the above, we can state our fourth sub-hypothesis, which is : H1.4. Developing countries with an Anglo-Saxon culture is more likely to adopt IFRS by appealing to the dual culture/politics; the notion of the political culture that draws the whole of values and of maneuvers linked at the way of practice the power.

Badie et al. (1992) defined culture as the precept of meaning commonly shared by citizens of the same nation. This definition allows us to consider that culture represents the code by which individuals translate acts and make them intelligible. We deduce so that culture, which rules the social field, is at the heart of different political regimes such as democracy. It is in this vision that the democratic culture should be placed as a specific aspect of political culture.

Given the lack of research around this notion, we will try to reconnect through this analysis, these concepts in order to realize the link between culture and politics and subsequently their effects on the development of accounting systems. From then on, it is feared that:

H1.5. the level of democratic culture has a significant influence on the choice of IAS / IFRS by developing countries.

\section{Behavioral factors}

Human behavior can be understood as the set of behaviors, that is, the assortment of responses, both psychological and active, to the contractions to which it is subjected. The individual perceives these contractions in different ways, depending on the environment in which he is immersed, according to his precept of personal motivations and according to his aptitudes. Through a behavioral pathway, the individual has concurrently a concern for stability and a concern for change that will enable it or not to improve the profitability of any choice such as the adoption of IFRS.

Therefore, we can pose our fourth hypothesis:

$\mathrm{H} 2$. Behavioral factors influence the use of international accounting standards

SY (201 1) in a article that studied the links between ownership of IAS / IFRS and organizational and managerial aspects of accounting, is widely recommended that the implementation of IFRS is 
the result of a managerial innovation. This author has also shown that "Accounting practices in IFRS spread quickly through the phenomenon of isomorphism, mimicry or coercive discursive (DiMaggio and Powell, 1983) and the phenomenon of fashion ( (Abrahamson, 1996) ." ". Riahi and Khoufi (2015).

In view of the above, the first sub-hypothesis to be verified:

H 2 .1. The likelihood that a developing country will adopt IFRS is significantly related to its overall level of innovation.

Usually, several studies suggest a century to explore the links that exist between the cultural values specific to any country and accounting values characterizing the financial accounting system to better explain the valuation and disclosure practices adopted by a firm, and based on the model of Hofstede and Gray (1988). In opposition to the above and to better address the objective of studying the behavioral determinants of IFRS adoption in developing countries, we will opt to identify the traits that may arise from an analysis of the possible links between the decision to adopt international accounting standards in developing countries and the accounting values that characterize them, in particular, conservatism. Indeed, the value of "conservatism" generally means a favor for a prudent approach to accounting valuation to face the uncertainty about future events. Basu (1997) defined conservatism as the desired attribute in financial statements, played a colossal role in accounting practice and theory, and provided other accounting principles, particularly the historical cost principle and the linking of Products for a multitude of centuries.

Nevertheless, the obvious explanations of conservatism remain narrow (Givoly and Hayn, 200 7).

In the modern literature, several clarifications have been addressed. Thus, for Watts and Zimmerman (1986, pp. 205-206) conservatism is "... the trend of accounting to publish, among the various possible alternatives, the lowest value in the assets and the highest value of the liabilities. Revenues should be recorded as late as possible and as soon as possible losses." As for Belkaoui (1985: 239) conservatism: "implies that it is preferable to account for assets and income at the lowest values and to record debts and charges at the highest values." Causal links between accounting conservatism and international accounting standards were widely known in analyzing the effects of the adoption of these standards Gray (1988) has deployed the G model. Hofstede (1984). He suggested that the attitudes of accountants or book values are presumed to have a link or stem from corporate values and that these accounting values in turn simulate accounting practice. In this light one can assume that cultural variables set by G.Hofsted (1984) but also behavioral ones can explain international differences in accounting systems before resorting to the adoption of IFRS. By extending and referring to the study of Hofstede (1984), Shushan (2010) and (Ben Aicha and Hamid, 2013) have pointed out, through their study, it is necessary to consider the cultural factor, with Accounting conservatism, in the choice of an accounting system. Consequently, it can be expected that the level of accounting conservatism will have an effect on the decision whether or not to adopt international accounting standards. It can be inferred, then the following hypothesis:

H2.2. The level of accounting conservatism has a significant influence on the choice of IAS / IFRS by developing countries : The lower the level of conservatism in a country, the more favorable it is to adopt IAS / IFRS.

Hazhar (2010) argued in a study of a sample of developing countries that there is an environmental problem from countries that could adopt IFRS. Indeed, the general security situation could determine whether or not a country adopts these standards. In this perspective, two other hypotheses remain to be tested :

H 2 .3. The more a country exhibits a high level of internal peace, the more it favors the adoption of IAS / IFRS.

H 2 .4. The level of probability of violent events has a significant influence on the choice of IAS / IFRS by developing countries.

Irvine et al. (2006) found that corruption in the United Arab Emirates has significantly contributed to the failure of this nation to adopt IFRS.
In addition, Riahi and Khoufi (2015) concluded that behavioral factors, mostly corruption, are more dominant than economic factors in the decision to adopt IAS / IFRS by developing countries. Their study was based on a sample of 76 developing countries. Following this idea, the following assumption takes place:

H 2. 5. The corruption perception index has a significant impact on the use of international accounting standards.

The governmental aspect continues to be an important postulate in moving towards international accounting standards. Riahi and Khoufi (2017) have largely proven the crucial weight of political governance in the adoption of IFRS by developing countries. Indeed, the results of their analyze, based on a sample of 108 developing countries, have reached the conclusion that the political governance, on the one hand, and the supremacy of taxation in the other, In guiding the choices of developing countries upon the face of the adoption of IAS / IFRS

Verriest et al. (2013) and Daske et al. (2008) conducted empirical research following the anticipated transitions of some European companies to international accounting standards. They examined the association between the governance structure of listed European companies and the early adoption of IFRS. The researchers concluded that the better governance the company has, the more favorable it is for early adoption of IFRS. In light of the above circumstances, the existence of a governance structure based on respected rules can also be included among the behavioral postulates of the adoption of IFRS. In this context, another hypothesis is estimated:

H.2.6. Developing countries with a rule-based governance structure, where priority and contract rights are reliably enforced and respected, are more likely to adopt IFRS.

\section{Research methodology}

\subsection{Sample and data set}

The perception of the effect of cultural and behavioral factors on the adoption of IFRS international accounting standards in developing countries is not, of course, information available in a database. To complete the study, it seems appropriate to be based on a sample of developing countries that has been selected by a fairly detailed process, from data provided by the official sites of the IASB and of the World Bank.

Our initial sample consists of all the developing countries that are among 144 countries (according to the list provided by the ISI) broken down into 75 countries adopting or planning to adopt IFRS 69 and others that may be distant Adoption of these standards. The adoption strategy (adoption, adoption and non-adoption of IFRS) for each country was identified after the IASB. The latter provided a method to detect the strategy of each country to adopt since there Has no database that defines and classifies countries into those adopting, adopting, and those that no longer adopt IFRS.

The phase of the constitution of our final sample (Table. 1) was performed as we have already cited following a procedure that uses the information founded on the official websites of the IASB and that of the World Bank.

Table 1: The Composition of the Final Sample

\begin{tabular}{ll} 
& Developing countries \\
\hline Starting Sample & 144 \\
Countries that adopt IFRS in 2013 & 40 \\
> Countries where information is unavailable & 10 \\
> remaining & 30 \\
Countries considering adopting IFRS & 36 \\
> Countries or information are unavailable & 10 \\
> remaining & 26 \\
Countries that remain far from adopting IFRS & 68 \\
> Countries or information are unavailable & 47 \\
> remaining & 21 \\
Final sample & 77 \\
\hline
\end{tabular}




\subsection{Measurement of variables and statistical approach}

i) The dependent variable

Analysis of the information found on the accounting systems of selected developing countries for our study allows us to discriminate countries that have adopted or plan to adopt IFRS against from those which have adopted these standards.

This distinction acknowledges us to define a dichotomous variable that takes the value 1 if a country has adopted or plans to adopt IFRS and zero if not

ii) The independent variables

According to the specific attributes of each country as well as the previous accounting studies, the following environmental factors will be experienced to explain the use of developing countries to IFRS including: cultural and behavioral factors.

Table 2: Summary of the Independent Variables Measures

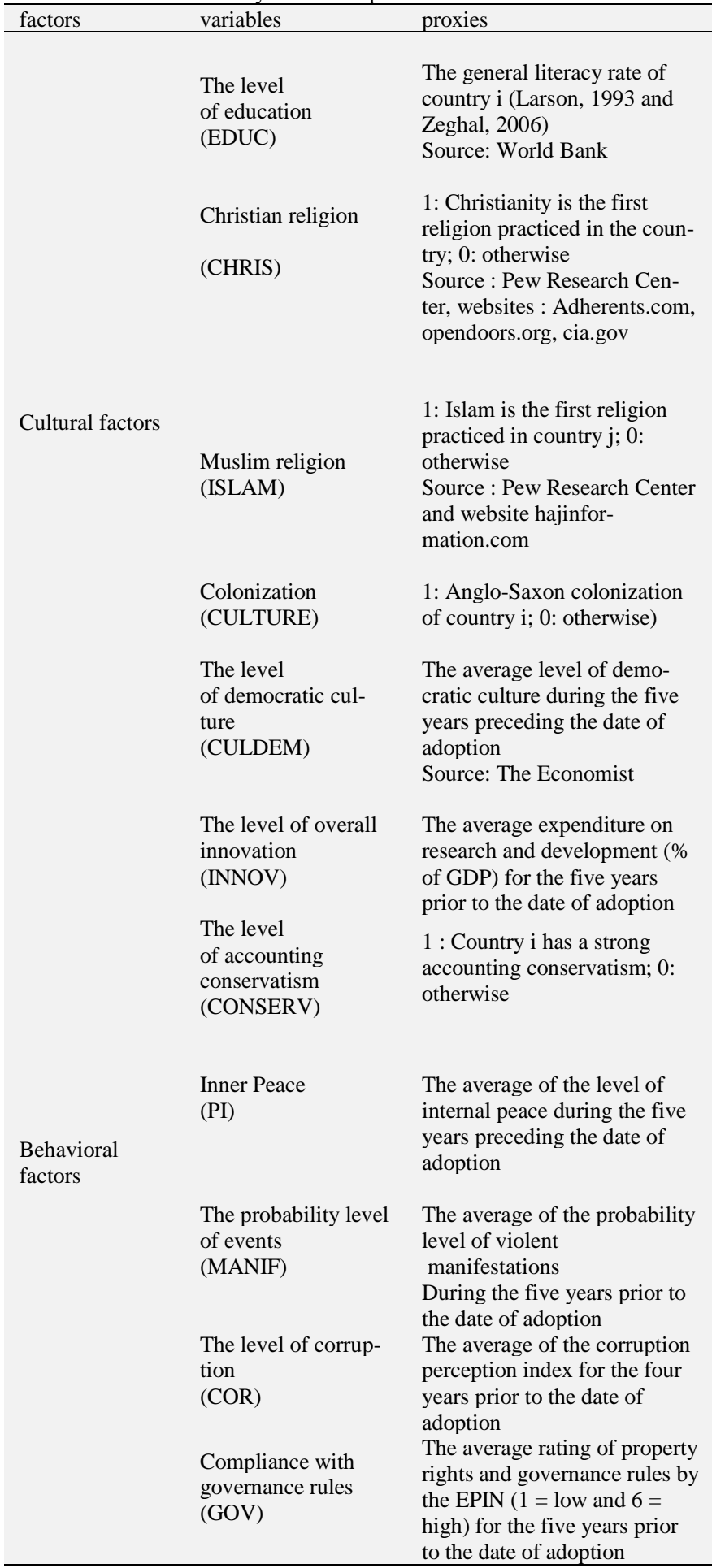

iii) Statistical tools

This research adopts a hypothetical-deductive methodology. It tries to confirm or reverse the assumptions made. After analyzing the data collected through a descriptive and comparative aspect between the two sample groups (countries that have adopted IFRS and those considering adoption vs. countries that do not adopt IFRS), research will be based on a multivariate analysis which represents the most captivating stage of the study since it makes it possible to judge the impact of the various variables taken as a whole.

Before embarking on this analysis we will conduct a test of the correlations between the different explanatory variables. If we do not detect any multicollinearity between these variables, we can introduce them in the model.

Since the dependent variable is binary, which takes 1 if a country has adopted or plans to adopt IFRS; 0 if not, the appropriate analysis would be an application of logistic regression.

$\log \left(\mathrm{P}_{\mathrm{i}} /\left(1-\mathrm{P}_{\mathrm{i}}\right)\right)=$

$\alpha_{0}+\alpha_{1}$ EDUC $_{\mathrm{i}}+\alpha_{2}$ CHRIS $_{\mathrm{i}}+\alpha_{3}$ ISLAM $_{\mathrm{i}}+\alpha_{4}$ CULTURE $_{\mathrm{i}}+\alpha_{5}$ CULDE

$\mathrm{M}_{\mathrm{i}}+\alpha_{6} \mathrm{INNOV}_{\mathrm{i}}+\alpha_{7} \mathrm{CONSERV}_{\mathrm{i}}+\alpha_{8} \mathrm{PI}_{\mathrm{i}}+\alpha_{9} \mathrm{MANIF}_{\mathrm{i}}+\alpha_{10} \mathrm{COR}$

$\mathrm{i}+\alpha_{11} \mathrm{GOV} \mathrm{i}+\varepsilon$

With:

$P_{i}:$ The likelihood of adoption of IAS / IFRS in 2013.

EDUC: The level of education

CHRIS: Religion Majority in each country is Christianity:

ISLAM: Religion Majority in each country is Islam

CULTURE: Colonization

CULDEM: The level of democratic culture

INNOV: The overall level of innovation

CONSERV: The level of accounting conservatism

PI: The level of inner peace

MANIF: The level of probability of manifestations

COR: The level of corruption

GOV: Good compliance with governance rules

$\alpha_{0}$ : Constant

iv) Country

$\alpha_{1}, \alpha_{2}, \alpha_{3}, \alpha_{4}, \alpha_{5}, \alpha_{6}, \alpha_{7}, \alpha_{8}, \alpha_{9}, \alpha_{10}, \alpha_{11}$ : parameters to be estimated in model

$\varepsilon$ : Residue.

\section{Analysis and discussion of empirical results}

Empirical evidence will be addressed using three statistical figures. The first one consists in the descriptive analysis which makes it possible to detect the global texture of each variable within the DC. The second figure is the univariate analysis. This tool is used to test the impact of each variable on the adoption of IFRS. The third analytical tool is the multivariate analysis method. She admits to perfecting the results of the univariate analysis by other empirical results from the multivariate regression model estimation.

\subsection{Presentation of the descriptive analysis: characteris- tics of two groups together}

Since the independent variables used are both numeric and dichotomous, the descriptive analyses of these variables are presented in two tables. Table 3 outlines the dichotomous variables while Table 4 shows the numeric variables. 
Table 3: Descriptive Statistics of Dichotomous Variables

\begin{tabular}{llll}
\hline variables & & frequencies & percentages \\
\hline \multirow{2}{*}{ ISLAM } & Muslim religion & 23 & 29.9 \\
& Non-Muslim Religion & 54 & 70.1 \\
& Christian religion & 43 & 55.8 \\
CHRIST & Non-Christian Religion & 34 & 44.2 \\
& & & \\
& Colonization & 25 & 32.5 \\
CULTURE & Anglo-Saxon & & \\
& Colonization & 52 & 67.5 \\
& Not Anglo-Saxon & 51 & 53.2 \\
CONSERV & Strong accounting conservatism & 41 & 46.8 \\
& Low accounting conservatism & 36 &
\end{tabular}

Table 4: Descriptive Statistics Numeric Variables

\begin{tabular}{llllll}
\hline variables & $\mathrm{N}$ & Average & Standard deviation & Minimum & Maximum \\
\hline EDUC & 77 & 80.1323 & 21.20093 & 19,03 & 100.00 \\
CUDEM & 77 & 5.0892 & 1.15943 & 1.88 & 8.13 \\
INNOV & 77 & .3497 & 0,48459 & 0,01 & 3.55 \\
PI & 77 & 2.5176 & 0,46181 & 1.66 & 4.26 \\
MANIF & 77 & 3.1347 & 0,74581 & 1.00 & 5.00 \\
COR & 77 & 3.3842 & 1.13510 & 1.63 & 7.13 \\
GOV & 77 & 1.4030 & 1.47579 & 0,01 & 3.50 \\
\hline
\end{tabular}

From the outset, the description of the variables related to the 77 developing countries objects of our sample has shown weak indicators on the cultural component on one hand and on the behavioral component, on the other. Indeed, if we compare the average level of inner peace of Luxembourg (degree $=4$ ) selected over the period 2008-2012 with that of 76 developing countries (one degree $=2.5176$ ), although it emphasizes " gap "Between developing countries and developed countries. Referring to Table 3, we also see the strong spread of non-Muslim religions. For behavioral attribute variables, they have in most cases low standard deviations. This signals the homogeneity of behaviors and attitudes at the DC's peoples. A primary analysis of the different behavioral variables reveals that DCs are very close, particularly at the inner peace having a standard deviation of 0.46283 . According to Global Peace Index, this index has a scale of 1 to 5 (high-low). The results from our research indicate an average of 2.5226, which reveals a mean level of inner peace in developing countries. It may be noted also that the level of likelihood of violent demonstrations, likewise, ranked the level of inner peace through Global Peace Index, is correspondingly high in developing countries. The average over the period from 2009 to 2012 is 3.1447 .

Furthermore, it is essential to say that corruption in the public sector is widely spread in developing countries (an average of 3.3750 over the period 2009-2012). In fact, the index was established by Transparency International (TI). It is on a scale of 0-10 a score of perception of corruption in the public sector for each country, where 0 means that the country is perceived as highly corrupt and 10 means that the country is perceived as very clean. The level of compliance with governance rules, a measure identified e by the World Bank reveals an average of 1.3927 over the period 2008-2012 is strictly very low if one refers to the scale of this score $(1=$ low to $6=$ high $)$. Regarding this variable, It should be noted that developing countries are partially homogeneous (a standard deviation of 1.50401) overlooked the proper respect for the rules of governance.

In addition, the overall level of innovation in developing countries is ample stared as low (an average of $0.3192 \%$ for the period 2006-2010) when compared with that of Sweden in 2010 that traces a level 3, $39902 \%$.

\subsection{Univariate analysis results: comparison between the two groups of DC}

The purpose of this analysis is to examine whether there is, in principle, a difference between the DC group having adopted or plans to adopt IFRS and the group of countries that have not yet adopted these standards. To achieve this comparison test of means between two independent samples should be taken. The normality Kolmogorov-Smirnov (Appendix 1) allowed us to identify the most appropriate technique to access the comparison of means. Indeed, if the distribution of a variable follows the normal distribution, the Student's t test is the appropriate technique to compare the means between the two groups of countries and if not the Mann-Whitney test using the order of appearance of the two samples observations would be more suitable. The parametric statistical Student t test (Table 5) was used to compare means of democratic culture the level of inner peace while the other variables will be processed using the Mann-Whitney test (see Table 6).

Table 5: Comparison of Two Groups of Developing Countries: Student's T Test

\begin{tabular}{|c|c|c|c|c|c|c|c|}
\hline \multicolumn{8}{|c|}{ Statistics of two groups } \\
\hline $\begin{array}{l}\text { varia- } \\
\text { bles }\end{array}$ & Adopt & $\begin{array}{l}\text { Aver- } \\
\text { age }\end{array}$ & $\begin{array}{l}\text { Standard } \\
\text { devia- } \\
\text { tion }\end{array}$ & $\mathrm{F}$ & $\begin{array}{l}* \\
\text { Sig. }\end{array}$ & $\begin{array}{l}\mathrm{t} \\
\text { Stu- } \\
\text { dent }\end{array}$ & Sig. \\
\hline \multirow{2}{*}{$\begin{array}{l}\text { CUDE } \\
\text { M }\end{array}$} & $\begin{array}{l}\text { Adop- } \\
\text { tion } \\
\text { No }\end{array}$ & 5.2108 & 1.17767 & \multirow{2}{*}{$\begin{array}{l}0, \\
110\end{array}$} & \multirow{2}{*}{$\begin{array}{l}074 \\
2\end{array}$} & \multirow[t]{2}{*}{1,515} & \multirow[t]{2}{*}{$\begin{array}{l}0.13 \\
4\end{array}$} \\
\hline & $\begin{array}{l}\text { Adop- } \\
\text { tion }\end{array}$ & 4.7651 & 1.06889 & & & & \\
\hline \multirow[b]{2}{*}{ PI } & $\begin{array}{l}\text { Adop- } \\
\text { tion }\end{array}$ & 2.4941 & $\begin{array}{l}0, \\
45692\end{array}$ & & & \multirow[b]{2}{*}{-0.729} & \multirow[b]{2}{*}{0.469} \\
\hline & $\begin{array}{l}\text { No } \\
\text { Adop- } \\
\text { tion }\end{array}$ & 2.5804 & $\begin{array}{l}0, \\
48021\end{array}$ & $\begin{array}{l}1,10 \\
1\end{array}$ & $\begin{array}{l}0.20 \\
5\end{array}$ & & \\
\hline
\end{tabular}

* Levene's test of equality of variances.

** Significant at $5 \%$.

Through the comparison of averages, we see that the countries that have adopted or are considering adopting IFRS are characterized by a high level of democratic culture $(52,108 \%$ ) compared to other developing countries $(47,651 \%)$.This profusely difference is not significant in the conventional $5 \%$ threshold. This is not consistent with what is expected in the assumptions.

Table 6: Comparison of Two Groups of Developing Countries: MannWhitney U Test

\begin{tabular}{|c|c|c|c|c|}
\hline \multicolumn{5}{|c|}{ Statistics of two groups } \\
\hline variables & ADOPT & average rank & $\mathrm{Z}$ & Sig. \\
\hline \multirow{2}{*}{ CHRIS } & Adoption & 42.25 & & \\
\hline & No Adoption & 30.33 & -2.420 & $0,016 *$ \\
\hline \multirow{2}{*}{ ISLAM } & Adoption & 36.44 & & \\
\hline & No Adoption & 45.83 & -2.070 & $0,038 *$ \\
\hline \multirow[b]{2}{*}{ CULTURE } & Adoption & 40.94 & & \\
\hline & No Adoption & 33.83 & -1.530 & 0,126 \\
\hline \multirow[t]{2}{*}{ EDUC } & Adoption & 44.68 & & \\
\hline & No Adoption & 23.86 & -3.637 & $0,000 *$ \\
\hline \multirow{2}{*}{ CONSERV } & Adoption & 33.63 & 3083 & 0000 * \\
\hline & No Adoption & 53.33 & -3.983 & 0,000 \\
\hline \multirow[t]{2}{*}{ COR } & Adoption & 43.43 & -2837 & $0005 *$ \\
\hline & No Adoption & 27.19 & -2.831 & $0.005 *$ \\
\hline \multirow{2}{*}{ GOV } & Adoption & 35.64 & 2155 & $0031 *$ \\
\hline & No Adoption & 47.95 & -2.155 & $0,031 *$ \\
\hline \multirow{2}{*}{ MANIF } & Adoption & 37.91 & 0705 & 0481 \\
\hline & No Adoption & 41,90 & $-0,705$ & 0.481 \\
\hline \multirow{2}{*}{ INNOV } & Adoption & 41.26 & -1447 & 0.148 \\
\hline & No Adoption & 32.98 & $-1.44 /$ & 0,148 \\
\hline
\end{tabular}

* Signifiant at $5 \%$.

In light of the results obtained in the Table 6 presented above, we see basically that there is a clear difference between the group of countries that have adopted or are considering adopting IFRS and those who have not adopted. Indeed the Christian religion, the 
level of corruption and the overall level of innovation have values culminating in countries adopting or planning to adopt IFRS. It should be noted that only the differences in variables (ISLAM), (CHRIS) (EDUC) (GOV) (CONSERV) and (COR) are significant at the 5\% level. These ranges are adapted to our assumptions previously estimated.

Nevertheless, the results in Table 6 exhibited a large gap between the two groups of developing countries in the sense that countries that have not adopted IFRS have the highest averages. These have shown that the level of violent protests in the first group (the countries that have adopted or plan to adopt IFRS) is smaller than the second group but with a difference that is devoid of significance $(\mathrm{sig}=0.481)$ the threshold of $5 \%$.

\section{Multivariate analysis}

The target of this analysis is to test the simultaneous impact of all variables and discern the validity of theoretical concepts. The test sample is a logistic regression model. To estimate the parameters of this regression, the technique usually used is not that of any ordinary square but the maximum likelihood technique. The application of the logistic regression generally desires the absence of co linearity between the independent variables. This phenomenon can be guessed, firstly, by the analysis of Pearson correlation matrix and the other, by the test VIF (Variance Inflation Factor) available in SPSS. The outcomes of these tests, as set out in Annex 2,reveal that the correlation coefficients are considerably smaller than 0.8 which is the boundary drawn by Kennedy (1985) and the FIV tests are all well below 3 . Therefore, the correlation between the variables does not show constraint.

Our approach consists in evaluating from Table 7 the overall characteristics of the logistics model and analysing it partially in order to verify our hypotheses on the other hand.

\begin{tabular}{llll}
\multicolumn{4}{c}{ Table 7: The Logistic Regression Result } \\
\hline variables & Coeff $\alpha$ & Wald & Sig. \\
\hline CHRIS & 2,739 & 2,573 & 109 \\
ISLAM & 1,423 & 776 & 378 \\
CULTURE & 477 & 164 & 685 \\
EDUC &, 054 & 4,270 &, $039 *$ \\
CUDEM & 562 & 745 & 388 \\
CONSERV & -3.900 & 6,499 &, $011 *$ \\
COR & 1,778 & 3,874 &, $049 *$ \\
GOV & -028 & 006 & 940 \\
PI & -968 & 521 & 470 \\
MANIF & $-2,544$ & 5,796 & $016 *$ \\
INNOV & -784 & 299 & 584 \\
Chi-square & $48.267 *$ & & \\
-2log-Likelihood & & & \\
Hosmer-Lemeshow test & 41.970 & & \\
R-square Cox \& Snell & & & \\
R-two Nagelkerke & 3,359 & & \\
\% of Good classification model & 0,466 & & \\
N & & & \\
\hline The probability is significant at the 0.05 & level & \\
& & & \\
\hline
\end{tabular}

Testing of the model evaluation parameters such presented in the table above, we allows to deduce that this model has a good overall significance (significant at the 5\% to reject the null hypothesis expressing the coefficients $(\alpha)$ are all equal to zero), an acceptable explanatory power (R-two Cox \&Snell and two RNagelkerke) and quality adjustment data (-2log-Likelihood, the Hosmer-Lemeshow test). The model can be judged through his correct prediction capacity. The latter is detected from the classification table. This table allows us to reach a classification percentage of the model that is the order of $72.7 \%$.Indeed, the model manages to correctly classify $72.7 \%$ of the sample .Des then it exposes a fairly altruistic prediction quality given to the logistic regression.

The partial analysis of the model will be based on independent variables maintained in the function logistics. All First, we find that the majority of the factors did not significantly affect the decision to adopt IFRS. Indeed, the level of education, level of accounting conservatism, the level of corruption and the level of violent manifestations appear not being the variables that simulate widely and significantly the decision to adopt IFRS developing countries. This result is not only no shypothesis (H1.1), (H2.2), (H 2.4) and $(\mathrm{H} 2.5)$ of the study but also the allegations of disregard of environmental factors the adoption of IFRS by DC. The high significance related to the variable accounting conservatism has shown that it seems a postulate that its evidence in the appropriation of IAS/IFRS by DC. ( $\mathrm{H} 2.4)$ and $(\mathrm{H} 2.5)$ of the study but also the allegations of disregard of environmental factors in the adoption of IFRS by the DC. The high significance related to the variable accounting conservatism has shown that it seems a postulate that its evidence in the appropriation of IAS/IFRS by DC. $(\mathrm{H} 2.4)$ and $(\mathrm{H} 2.5)$ of the study but also the allegations of disregard of environmental factors in the adoption of IFRS by the DC. The high significance related to the variable accounting conservatism has shown that it seems a postulate that its evidence in the appropriation of IAS / IFRS by DC.The high significance related to the variable accounting conservatism has shown that it seems a postulate that its evidence in the appropriation of IAS/IFRS by DC .The high significance related to the variable accounting conservatism has shown that it seems a postulate that its evidence in the appropriation of IAS/IFRS by DC.

On the other hand, the result related to religion has put the statements of previous studies (C. Nobes 1998, A. Lau and R. Ma 1997, RM Haniffa and TF Cooke 2002, B. Maali et al. (Ayadi and Ben Salem, 2012), about his affluence in the decision to adopt the international accounting standards at issue. Hence the hypothesis (H1.2) and (H1.3) are entirely invalidated.

Although the positive sign of the coefficient of variables for colonization and the level of democratic culture was in line with our expectations and suggests strong cultural factors (coefficient $=$ 0.477 and 0.562 respectively), these variables do not appear to be forced In determining the decision to adopt IFRS ( $\mathrm{Sig}=0.685$ and 0.388 respectively). To this end, our hypotheses (H1.4) and (H1.5) are partially confirmed. The results we exhibit also, due to are low $\mathrm{s}$ significance $\mathrm{s}$ the level of innovation overall, the level of peace interior, and $\mathrm{u}$ weight compliance with government practices, that our assumptions (H.2.1), (H.2.3) and (H.2.6) are fully reversed. In fact, developing countries maintaining a high degree of these variables appear the least likely to adopt IFRS. The non-significant effect of the variable outlining the overall level of innovation can be guessed by the ' exhaustion and high dispersion degrees of innovation in developing countries innovation in developing countries .innovation in developing countries.

The non-significance of these variables can be explained also by the puberty of the majority of developing countries face the movements of the boom in global innovation of the country with one hand and the marginalization of the government and peaceful pace of the other as well as attempts pushing the spread of good governance guides in these countries.

Empirical spans the variable drawing the level of violent demonstrations can be explained by the expansion of multinational corporations, which seek the adoption of high quality standards in particular IFRS in an environment stable.

The staves adjoining the variables (GOV) and (PI) totally negated our hypotheses. The level of internal peace and the degree of compliance with governance rules do not prove to be solid factors postulating the decision to adopt IFRSs in developing countries. Accordingly, it is sparkling as the results of the multivariate analysis will recede largely from those of the univariate analysis. It appears that behavioral factors, of which conservatism is the most robust variable, are more distinguished than cultural factors behind the decision to adopt IFRSs by developing countries. 


\section{Conclusion}

IFRS has designed appropriate guidance for organizations that are increasingly rewarding themselves in distant markets and have long supported the costs of adapting their accounting assessments to make them comparable and understandable to recipients. Given that a large number of developed countries have been heavily involved in the process of implementing accounting instructions that take into account their environmental peculiarities, a minority of developing countries is being led to adopt these instructions. In this paper, our article aims to discern the effect of the main cultural and behavioral factors that could simulate the decision of the adoption of IFRS by the developing countries. Furthermore, we have been inclined to concede the different cultural and behavioral variables that are potentially likely to affect the adoption of IFRS in these countries.

Based on a logistic regression for a sample of 77 developing countries, empirical findings have shown that conservatism is the only factor that is significantly related to the decision to adopt IFRS.

The interactions between cultural and behavioral factors led to the robustness of the behavioral attribute in the decision to adopt IFRSs in developing countries. This work asserted that developing countries with a high level of conservatism is more likely to adopt or consider adopting IFRS. These developments have allowed us to see that the more vigorous the level of conservatism in a developing country, the more cautious it is to adopt the IAS / IFRS standards. In this regard, it appears that the majority of developing countries that have adopted IAS / IFRS have a low level of conservatism. This suggests that the level of accounting conservatism has a significant influence on the choice of IAS / IFRS by developing countries: the more a country exhibits a high level of conservatism, the more reluctant it is to adopt IAS / IFRS.

The empirical ends of our study, which are characterized by divergent outcomes, have allowed us to conclude that the decision to adopt IFRS by the developing countries does not reflect a reasonable and impeccable tie with the structure of a company, a nation. It is often the result of an inclination of legitimacy on the part of these countries in the international sphere.

This conclusion is in harmony with the writings which have fully justified that countries do not necessarily choose the practices most appropriate to the demands and economic demands of the moment but those that are socially correlated. This isomorphism is only a continuation of an evocation which reproduces a given behavior.

\section{References}

[1] ALHASHIM, Dhia D. and JEFFREY, S. Arpan. (1992). International Dimensions of Accounting.

[2] ASHRAF, Junaid and GHANI, Waqar I. (2005). Corporate governance, business group affiliation, and firm performance: descriptive evidence from Pakistan. East Asian Bureau of Economic Research.

[3] ASKARY, Saeed, POUNDER, James S., and YAZDIFAR, Hassan. (2008). Influence of culture on accounting uniformity among Arabic nations. Education, Business and Society: Contemporary Middle Eastern Issues, vol. 1, n ${ }^{\circ} \quad 2, \quad$ p. 145-154. https://doi.org/10.1108/17537980810890329.

[4] BADIE, Bertrand and SMOUTS, Marie-Claude. (1992). Le retournement du monde: sociologie de la scène internationale. Presses de la Fondation nationale des sciences politiques.

[5] BASU, Sudipta. (1997).The conservatism principle and the asymmetric timeliness of earnings 1. Journal of accounting and economics, vol. 24, $\mathrm{n}^{\circ}$ 1, p. 3-37. https://doi.org/10.1016/S01654101(97)00014-1.

[6] BELKAOUI, Ahmed. (1985).International accounting: issues and solutions. Praeger Pub Text.

[7] BENAICHA, badis and HAMID, fatma. (2013). Facteur culturel et pratiques comptables en Algerie. Revue de chercheur, $\mathrm{n}^{\circ} 13$. https://doi.org/10.12816/0005885.

[8] BENSALEM, Rahma and AYADI, Salma Damak. (2012). La culture et le recours aux IAS/IFRS. La Revue des Sciences de Gestion, vol. 254, n 2 , p. 39-48. https://doi.org/10.3917/rsg.254.0039.
[9] CHAMISA, Edward E. (2000). The relevance and observance of the IASC standards in developing countries and the particular case of Zimbabwe. The International Journal of Accounting, vol. 35, $\mathrm{n}^{\circ}$ 2, p. 267-286. https://doi.org/10.1016/S0020-7063(00)00049-2.

[10] CHOI, F. D. S. and MUELLER, G. G. (1992). International Accounting. New Jersey: Prentice-Hall.

[11] CHOUCHANE, Besma. (2010). Pertinence des normes comptables IAS/IFRS au contexte culturel tunisien.

[12] DASKE, Holger, HAIL, Luzi, LEUZ, Christian, and al. (2008). Mandatory IFRS reporting around the world: Early evidence on the economic consequences. Journal of accounting research, vol. 46, no 5 , p. 1085-1142. https://doi.org/10.1111/j.1475679x.2008.00306.x.

[13] DIMAGGIO, Paul J. and POWELL, Walter W. (2000).The iron cage revisited-Institutional isomorphism and collective rationality in organizational fields (Reprinted from the American Sociological Association vol 48, pg 147-160, 1983). ADVANCES IN STRATEGIC MANAGEMENT, VOL 17, p. 143-166.

[14] GERNON, H., MEEK, G., and MUELLER, G. (1987). Accounting: An International Perspective Homewood. Il: Irwin.

[15] GIVOLY, Dan, HAYN, Carla K., and NATARAJAN, Ashok. (2007).Measuring reporting conservatism. The Accounting Review, vol. 82, $\mathrm{n}^{\circ}$ 1, p. 65-106. https://doi.org/10.2308/accr.2007.82.1.65.

[16] HAMID, Shaari, CRAIG, Russell, and CLARKE, Frank. (1993).Religion: a confounding cultural element in the international harmonization of accounting? Abacus, vol. 29, $\mathrm{n}^{\circ}$ 2, p. 131-148 https://doi.org/10.1111/j.1467-6281.1993.tb00427.x.

[17] HANIFFA, Rozaini Mohd and COOKE, Terry E. (2002). Culture, corporate governance and disclosure in Malaysian corpora$\begin{array}{llllll}\text { tions. Abacus, } & \text { vol. } \quad 38, \quad \mathrm{n}^{\circ} & 3, & \text { p. } & 317-349\end{array}$ https://doi.org/10.1111/1467-6281.00112.

[18] HASSABELNABY, Hassan R., EPPS, Ruth W., and SAID, Amal A. (2003).The impact of environmental factors on accounting development: an Egyptian longitudinal study. Critical Perspectives on Accounting, vol. $14, \quad \mathrm{n}^{\circ} \quad 3, \quad$ p. 273-292. https://doi.org/10.1006/cpac.2002.0530.

[19] Hazhar P., SHARIF. (2010). Factors affecting on the Adoption of International Financial Reporting Standards: Iraqi Evidence. Thèse de doctorat. Universiti Utara Malaysia.

[20] HOFSTEDE, Geert. (1984). Culture's consequences: International differences in work-related values. sage.

[21] HOVE, Mfandaidza R. (1986).Accounting practices in developing countries: colonialism's legacy of inappropriate technologies. International Journal of Accounting Education and Research, vol. $22, \mathrm{n}^{\circ} 1$, p. $81-100$

[22] IRVINE, Helen J. and LUCAS, Natalie. (2006).The globalization of accounting standards: the case of the United Arab Emirates. Faculty of Commerce-Papers, p. 219 https://doi.org/10.1142/9789812819611 0004 .

[23] LAU, Amy and MA, Ronald. (1997).A broad perspective on Financial Reporting in the Pacific Asia. Financial Reporting in the Pacific Asia Region World Scientific: Accounting and Business in Asia, $\mathrm{p}$. 55-92.

[24] LOPES, Patrícia Teixeira and RODRIGUES, Lúcia Lima. (2007). accounting for financial instruments: An analysis of the determinants of disclosure in the Portuguese stock exchange. The International Journal of Accounting, vol. 42, $\mathrm{n}^{\circ}$ 1, p. 25-56. https://doi.org/10.1016/j.intacc.2006.12.002.

[25] MAALI, Bassam, CASSON, Peter, and NAPIER, Christopher. (2006). Social reporting by Islamic banks. Abacus, vol. 42, no 2 , p. 266-289. https://doi.org/10.1111/j.1467-6281.2006.00200.x.

[26] NOBES, Christopher W. (1983). A judgemental international classification of financial reporting practices. Journal of Business Finance \& Accounting, vol. $10, \quad \mathrm{n}^{\circ} \quad 1, \quad$ p. $1-19$. https://doi.org/10.1111/j.1468-5957.1983.tb00409.x.

[27] NOBES, Christopher. (1998).Towards a general model of the reasons for international differences in financial reporting. Abacus, vol. 34, no 2, p. 162-187. https://doi.org/10.1111/1467-6281.00028.

[28] NOBES, Christopher. (2004). on accounting classification and the international harmonisation debate. Accounting, Organizations and Society, vol. $29, \mathrm{n}^{\circ} 2$, p. 189-200 https://doi.org/10.1016/S03613682(03)00045-X.

[29] Perera, M. H. B, and Velayutham, S. (2004). The influence of emotions and culture on accountability and governance. Corporate Governance: The international journal of business in society, 4(1), 52-64. https://doi.org/10.1108/14720700410521961.

[30] RIAHI, Olfa and KHOUFI, Walid. (2015). The role of the economic and behavioral circumstances in the IAS/IFRS's adoption (the case of developing countries).International Journal of Accounting 
and Economics Studies, vol. 3, $\mathrm{n}^{\mathrm{o}}$ 1, p. 69-77. https://doi.org/10.14419/ijaes.v3i1.4601.

[31] RIAHI, Olfa and KHOUFI Walid. (2017). the power of political governance and the adoption of international accounting standards. International Journal of Business \& Economic Strategy, vol.6, pp.9-23.

[32] SAUDAGARAN, Shahrokh M. (2009). International accounting: A user perspective. $\mathrm{CCH}$.

[33] SY, Issiaga Thiam. (2011). Etude des liens entre l'appropriation des normes IAS/IFRS et les dimensions organisationnelles et managériales des services comptables. Thèse de doctorat. Conservatoire national des arts et metiers-CNAM.

[34] TAPLIN, Ross, TOWER, Greg, et HANCOCK, Phil. (2002). Disclosure (discernibility) and compliance of accounting policies: Asia-Pacific evidence. In: Accounting Forum. Blackwell Publishers Ltd., p. 172-190. https://doi.org/10.1111/1467-6303.00085.

[35] Verriest, A., Gaeremynck, A., \& Thornton, D. B. (2013). The impact of corporate governance on IFRS adoption choices. European accounting review, 22(1), 39-77. https://doi.org/10.1080/09638180.2011.644699.

[36] Walton, P., Haller, A., \& Raffournier, B. (2003). International accounting. Cengage Learning EMEA.

[37] WONG, Peter. (2004).Challenges and successes in implementing international standards: achieving convergence to IFRSs and ISAs, New York: IFAC.

[38] ZEGHAL, Daniel and MHEDHBI, Karim. (2006). An analysis of the factors affecting the adoption of international accounting standards by developing countries. The International Journal of Accounting, vol. 41, $\mathrm{n}^{\mathrm{o}} \quad 4, \quad \mathrm{p}$. 373-386. https://doi.org/10.1016/j.intacc.2006.09.009. 